\title{
Preparation of Palm Oil Mill Effluent Sludge Biochar for the Treatment of Landfill Leachate
}

\author{
Mohammed J.K. Bashir ${ }^{1 *}$, Jing Wei Wong ${ }^{l}$, Sumathi Sethupathi ${ }^{l}$, Ng Choon Aun $^{l}$, Lim Jun \\ $W e i^{2}$ \\ ${ }^{1}$ Department of Environmental Engineering, Faculty of Engineering and Green Technology (FEGT), \\ Universiti Tunku Abdul Rahman, 31900 Kampar, Perak, Malaysia. \\ ${ }^{2}$ Department of Fundamental and Applied Sciences, Universiti Teknologi PETRONAS, 32610 Seri \\ Iskandar, Perak Darul Ridzuan, Malaysia
}

\begin{abstract}
In recent years, landfilling has emerged as the most widely employed method for municipal solid waste disposal especially in ASEAN countries. However, due to the presence of refractory compounds in stabilized landfill leachates which results in the inefficiency of biological treatment methods, other alternatives such as physico-chemical treatment methods are being look into and adsorption method seems promising. Nevertheless, the raw materials used for the preparation of adsorbents in the industry are usually non-renewable materials thus resulting in high operational costs. Therefore, present study evaluates the ability of palm oil mill effluent sludge (POMES) derived biochar in the treatment of chemical oxygen demand (COD), color and ammoniacal nitrogen $\left(\mathrm{NH}_{3}-\mathrm{N}\right)$ from stabilized landfill leachate obtained from Sahom landfill located in Kampar, Perak, Malaysia using response surface methodology (RSM) technique. It was found that the removal efficiency of the leachate pollutants by POMES biochar is highly dependent on the production process such as temperature and holding time. In this study, $44.26 \%$ of COD, $70.20 \%$ of color and $30.56 \%$ of $\mathrm{NH}_{3}-\mathrm{N}$ were removed from stabilized landfill leachate via optimized biocharat $452^{\circ} \mathrm{C}$ temperature and 66 minutes of holding time.
\end{abstract}

\section{Introduction}

From time to time, Malaysia faces serious complications with its municipal solid waste (MSW) originated from various sources such as commercial, residential, agricultural and industrial. The trend of the waste produced annually is increasing at an alarming rate which signifies the need for MSW management and a compelling strategy to overcome the current situation. The scenario worsens with the continual increase in both economy and population growth which means more waste to be produced. The waste generation in Malaysia is expected to rocket up from $292 \mathrm{~kg} /$ capita in 2000 to $511 \mathrm{~kg} /$ capita in 2025 and at the time being, landfilling of waste is still the main waste disposal solution for Malaysia which accounts for up to $80 \%$ of total waste disposal methods [1]. In the year 2020 , landfilling is

*Corresponding author: jkbashir@utar.edu.my 
still expected to uphold about $65 \%$ of total waste disposal methods in the country according to the $10^{\text {th }}$ Waste Management Policy of Malaysia Plan, 2010 to 2020. The popularity of using this method for waste disposal is due to certain advantages such as low cost and easy disposal, however the long-standing drawback associated with municipal landfill is the selfgeneration of highly contaminated leachate which is formed by the mixing of water sources with the wastes in the landfill either through an open landfill or the top cap of a complete landfill. This highly contaminated water may contain large quantities of ammonia, heavy metals, suspended solids, dissolved organic matter, xenobiotic organic substances, phenols and many more [2]. The high strength of $\mathrm{COD}$ and $\mathrm{NH}_{3}-\mathrm{N}$ resulted from the decomposition of organic matters are considered the best way to characterize and analyse a leachate sample due to the fact that these are the pollutants that play the role for main chemical features of an environmental threat. As a result, stringent discharge standards have been imposed by the Malaysian government which leaves conventional treatments insufficient to fulfil the stipulated requirement. Therefore this leads to various leachate treatment techniques being employed worldwide.

In spite knowing the fact that the whole treatment process for landfill leachate is an extremely sophisticated procedure and requires high operational costs, leachate treatment is being done and widely used to minimize its environmental impacts.Different processes have been employed for example chemical oxidation, coagulation-flocculation, ion exchange, adsorption and electrochemical treatment. Of all, adsorption process is the most extensively used technique worldwide when it comes to the removal of recalcitrant organic compounds from landfill leachate [2]. Having certain significant properties such as highly porous structure, low acid/base reactivity, thermo-stability, high surface reactivity, relatively low cost involvement, adsorption process has emerged as the most promising technique in removing landfill leachate pollutants having abilities to attract pollutants onto and into its surface using chemical and physical interactions. Adsorbents that are commercially available in the market are expensive and mostly derive from non-renewable sources such as coal, so the use of conventional materials such as agricultural waste or biomasses that are readily available locally in large quantity such as bamboo, pecan shell, oil palm fibre and sugarcane bagasse could be the solution to this matter. These materials can be chemically and physically modified to become a new adsorbent with minimum expenditure.

Up to date, no study has been made on utilizing POMES-derived biochar for the treatment of highly contaminated landfill leachate. Therefore, due to the promising adsorption properties of biochar produced from biomass for example POMES, this study focuses on the preparation and effectiveness of using POMES biochar to remove the complex and highly contaminated pollutants from landfill leachate.

\section{Materials and methods}

\subsection{Site characteristic and leachate sampling}

The leachate samples were collected from Sahom landfill site, located in Kuala Dipang in Perak, Malaysia. The operation of Sahom landfill has begun ever since 1992 with a total landfilling area of approximately 37 acres. The anaerobic landfill mainly serves the waste collected within Kampar district and has recorded a population service to a total of 101,183 people with an average of 100 tonnes of MSW received daily. The collected leachate samples were instantaneously transported to the Environmental Laboratory and stored at $4^{\circ} \mathrm{C}$ in minimal light and air exposure condition in order to reduce the chemical and biological changes. The leachate was characterized according to the Standard Method for 
the Examination of Water and Wastewater [3]. In total, three samples were collected and characterised from October 2015-March 2017.For chemical oxygen demand (COD), ammoniacal-nitrogen $\left(\mathrm{NH}_{3}-\mathrm{N}\right)$, color, Biochemical Oxygen Demand $\left(\mathrm{BOD}_{5}\right)$, turbidity, total suspended solids (SS) and $\mathrm{pH}$ as presented in Table 1. Based on leachate characteristics indicted in Table 1, Sahom landfill leachate is classified as stabilised leachate.

Table 1.Sahom landfill leachate characteristics.

\begin{tabular}{ccc}
\hline Parameters & Average Value & $\begin{array}{c}\text { Malaysian Discharge Standards } \\
\text { for Leachate }\end{array}$ \\
\hline Temperature & $24.8^{\circ} \mathrm{C}$ & $40^{\circ} \mathrm{C}$ \\
$\mathrm{pH}$ & 8.06 & $6.0-9.0$ \\
Turbidity & $207 \mathrm{NTU}$ & - \\
$\mathrm{BOD}_{5}$ & $37 \mathrm{mg} / \mathrm{L}$ & $20 \mathrm{mg} / \mathrm{L}$ \\
$\mathrm{COD}^{\circ}$ & $549 \mathrm{mg} / \mathrm{L}$ & $400 \mathrm{mg} / \mathrm{L}$ \\
$\mathrm{BOD}_{5} / \mathrm{COD}$ & 0.067 & 0.05 \\
$\mathrm{Color}$ & $1020 \mathrm{Pt} / \mathrm{Co}$ & $100 \mathrm{Pt} / \mathrm{Co}$ \\
Total Suspended & $95 \mathrm{mg} / \mathrm{L}$ & $50 \mathrm{mg} / \mathrm{L}$ \\
$\mathrm{Solids}$ & & $5 \mathrm{mg} / \mathrm{L}$ \\
$\mathrm{NH}_{3}-\mathrm{N}$ & $144 \mathrm{mg} / \mathrm{L}$ &
\end{tabular}

\subsection{Char preparation}

The palm oil mill effluent sludge (POMES) was collected from Tian Siang Oil Mill Sdn. Bhd. Located in Air Kuning, Perak, Malaysia. The POMES was obtained from the anaerobic digestion system and was evenly spread on 3 metal trays and air-dried for 3 days to remove bad odor and moisture. The POMES was later screened to the desired mesh size of $1-2 \mathrm{~mm}$ and further dried in an oven at $105^{\circ} \mathrm{C}$ for 24 hours to remove the water content because presence of high moisture content in the sample will result in production of fuel gases and affect the production of biochar [4]. Then, the dried POMES were allowed to cool down before being stored in a dry bucket and sealed up to minimize moisture contamination and fungal infection.

The prepared precursor was later measured for weight and loaded in a stainless steel vertical tubular and placed in the tube furnace in the carbonization unit. The carbonization process was conducted under purified nitrogen $\left(\mathrm{N}_{2}\right)$ supply with the flow rate at $300 \mathrm{ml} / \mathrm{min}$ using control valves. The range of pyrolysis temperature $\left(300-600^{\circ} \mathrm{C}\right)$ and holding time (60-180 $\mathrm{min}$ ) were taken on the basis of literature [5]. Carbonization process was carried out based on the experimental design by a standard RSM method.

\subsection{Design of experiment (DOE)}

Design-Expert ${ }^{\circledR}$ Software Version 10.0 by Stat-Ease, Inc., Minneapolis, USA was used to generate a series of experiments to be conducted by the different combinations of experimental variables using a standard response surface methodology (RSM) technique known as central composite design (CCD). RSM utilizes the combination of statistical and mathematical workings to optimize and design an experiment based on numerous experimental variables with minimum amount of experimental runs and analyse the relationship between the dependent and independent variables [6].CCD was used to verify the effective parameters with definite number of experiments and analysed the interface 
between the parameters. By using CCD the experiment could be designed based on $2^{\mathrm{n}}$ factorial runs with 2 naxial runs and $n_{\mathrm{c}}$ center runs (replicate experimental runs), whereby $\mathrm{n}$ indicates the number of factors involved. In this study, POMES biochar preparation conditions were found to be important criteria affecting the characteristics of biochar produced. The two parameters under analysis include heating temperature and holding time. Therefore the full experimental matrix consists of 4 factorial points, 4 axial points with 5 replicates at the center points summing up to 13 experimental runs as denoted by using Equation 1:

$$
N=2^{\mathrm{n}}+2 \mathrm{n}+\mathrm{n}_{\mathrm{c}}=2^{2}+2(2)+5=13 \text { runs }
$$

In Equation $1, \mathrm{~N}$ is the total number of experimental runs, and $\mathrm{n}$ is the number of affecting factors. Numerous variables may affect the response of the system studied and it is practically impossible to identify and control the small contributions from each one. Therefore, the independent variables are coded as $-\alpha,-1,0,+1,+\alpha$ interval which indicates the low, center and high level of each variableswhere $\alpha$ is the axial points from the center which makes the design rotatable.

\subsection{Model fitting and statistical analysis}

The analysis of variance (ANOVA) is a reliable way to evaluate the quality of a fitted model by examining the statistical significance of the equations as well as the degree of fitness of the equations. It depicts the co-relation between the actual results obtained with the equation which encapsulates all the responses and variable denoted in the equation. As replicates of the central point are made, it is possible to calculate the pure error associated with the repetitions since variation occurs due to pure error which could be defined as unpredictable changes and variables that occur during the experiment. In general, a model will be well fitted to the experimental data if it presents a significant regression and a nonsignificant lack of fit.

\subsection{Batch equilibrium studies}

The prepared biochar under respective variables was added into the leachate samples to identify the efficiency of the biochar. $0.2 \mathrm{~g}$ of biochar was added into a $250 \mathrm{~mL}$ Erlenmeyer Flask with $50 \mathrm{~mL}$ of leachate sample and was shaken for 3 hours with rotating speed of 200rpm using the orbital shaker (IKA KS 260 B S2, Germany). The mixture was then filtered using filter paper with pore size of $90 \mu \mathrm{m}$. The filtrate was then tested for the concentration of $\mathrm{COD}$, color, and $\mathrm{NH}_{3}-\mathrm{N}$ to determine the removal efficiency of biochar. The removal efficiency of the color, $\mathrm{COD}$, ammoniacal-nitrogen were identified using Equation 2. Each experiment was repeated for three times to obtain an average reading.

$$
R(\%)=\frac{C_{i}-C_{f}}{C_{i}} \times 100
$$

In Equation 2, $R$ is the removal efficiency in percentages and $\mathrm{C}_{\mathrm{i}}$ and $\mathrm{C}_{\mathrm{f}}$ are the initial and final concentrations of COD $(\mathrm{mg} / \mathrm{L}), \mathrm{NH}_{3}-\mathrm{N}(\mathrm{mg} / \mathrm{L})$ and color $(\mathrm{PtCo})$. 


\section{Result and discussion}

\subsection{Leachate characteristics}

The initial measurements recorded high values of COD, color and ammoniacal-nitrogen values. The $\mathrm{BOD}_{5}$ value is relatively low and thus resulting in low $\mathrm{BOD}_{5} / \mathrm{COD}$ ratio. Due to these characteristics, Sahom landfill leachate was thus classified as matured landfill leachate with $\mathrm{pH}$ value larger than 7.5 , COD reading lower than $4000 \mathrm{mg} / \mathrm{L}, \mathrm{BOD}_{5} / \mathrm{COD}$ ratio below 0.1 and heavy metal concentration lower than $2 \mathrm{ppm}$. The organic components present in the stabilized landfill leachate were mostly non-biodegradable as they contain refractory compounds. As such, conventional biological treatment methods are no longer adequate and efficient to be utilized for Sahom landfill leachate treatment, therefore physicochemical process in particular carbon adsorption becomes one of the compatible alternative for stabilized landfill leachate treatment.

\subsection{Preparation of POMES derive biochar using (RSM)}

The responses (pollutant percentage removal) for respective experimental runs were examined and tabulated in Table 2 . The equations with coded factors used by the software to estimate and maximize the removal efficiency of the dependent responses COD removal $\left(\mathrm{Y}_{1}\right)$, color removal $\left(\mathrm{Y}_{2}\right)$ and $\mathrm{NH}_{3}-\mathrm{N}$ removal $\left(\mathrm{Y}_{3}\right)$ with pyrolysis temperature $\left(\mathrm{X}_{1}\right)$ and holding time $\left(\mathrm{X}_{2}\right)$ are given in Equations 3, 4 and 5:

$$
\begin{aligned}
& \mathrm{Y}_{1}=41.76+6.77 *\left(X_{1}\right)-0.90 *\left(X_{2}\right)+0.080 *\left(X_{1}\right) *\left(X_{2}\right)-17.20 *\left(X_{1}^{2}\right)+3.94 *\left(X_{2}^{2}\right) \\
& \mathrm{Y}_{2}=69.29+1.88 *\left(X_{1}\right)-0.99 *\left(X_{2}\right)+0.075^{*}\left(X_{1}\right) *\left(X_{2}\right)-8.81 *\left(X_{1}^{2}\right)+2.17 *\left(X_{2}^{2}\right) \\
& \mathrm{Y}_{3}=26.53-0.19 *\left(X_{1}\right)-1.41 *\left(X_{2}\right)-2.50 *\left(X_{1}\right) *\left(X_{2}\right)-4.62 *\left(X_{1}^{2}\right)+1.72\left(X_{2}^{2}\right)
\end{aligned}
$$

Positive terms represent synergistic effect, whereas negative terms represent antagonistic effect [6]. The significance of quadratic models for all responses was examined using ANOVA and the results are presented in Table 3.

Table 2. Experimental Design Matrix coupled with respective parameter readings.

\begin{tabular}{cccccc}
\hline \multirow{2}{*}{$\begin{array}{c}\text { Experimental } \\
\text { Run }\end{array}$} & \multicolumn{2}{c}{ Factors } & \multicolumn{3}{c}{ Response (Removal Efficiency, \%) } \\
\cline { 2 - 6 } & $\begin{array}{c}\text { Temperature } \\
\left({ }^{\mathbf{C}} \mathbf{C}\right)\end{array}$ & $\begin{array}{c}\text { Holding Time } \\
(\mathbf{m i n})\end{array}$ & $\begin{array}{c}\text { COD, } \\
(\mathbf{m g} / \mathbf{L})\end{array}$ & $\begin{array}{c}\text { Color, } \\
\mathbf{( P t C o})\end{array}$ & $\begin{array}{c}\mathbf{N H 3 - N} \\
(\mathbf{m g} / \mathbf{L})\end{array}$ \\
\hline 1 & 300 & 60 & 22.94 & 61.83 & 25.56 \\
2 & 300 & 180 & 21.65 & 59.94 & 22.56 \\
3 & 375 & 120 & 30.93 & 65.32 & 24.32 \\
4 & 450 & 90 & 42.78 & 70.14 & 26.91 \\
5 & 450 & 120 & 43.40 & 69.90 & 26.32 \\
6 & 450 & 120 & 42.53 & 69.57 & 27.82 \\
7 & 450 & 120 & 43.40 & 69.90 & 26.05 \\
8 & 450 & 120 & 42.53 & 69.57 & 26.37 \\
9 & 450 & 120 & 43.30 & 69.90 & 27.46 \\
10 & 450 & 150 & 39.18 & 68.16 & 26.25 \\
11 & 525 & 120 & 40.46 & 67.49 & 25.67 \\
12 & 600 & 60 & 35.64 & 65.37 & 24.81 \\
13 & 600 & 180 & 34.67 & 63.78 & 21.80 \\
\hline
\end{tabular}


Table 3. ANOVA analysis for response surface quadratic model ANOVA

\begin{tabular}{cccccccc}
\hline & Source & $\begin{array}{c}\text { Sum of } \\
\text { Square }\end{array}$ & $\begin{array}{c}\text { df } \\
*\end{array}$ & $\begin{array}{c}\text { Mean } \\
\text { Square }\end{array}$ & F value & p-value & Remarks \\
\hline COD & Model & 678.09 & 5 & 135.62 & 32.37 & 0.0001 & Significant \\
& Lack of Fit & 28.62 & 3 & 9.54 & 53.63 & 0.0011 & Significant \\
Color & Model & 138.55 & 5 & 27.71 & 51.64 & $<0.0001$ & Significant \\
& Lack of Fit & 3.63 & 3 & 1.21 & 36.99 & 0.0022 & Significant \\
$\mathbf{N H}_{3}-\mathbf{N}$ & Model & 32.67 & 5 & 6.53 & 9.04 & 0.0058 & Significant \\
& Lack of Fit & 2.61 & 3 & 0.87 & 1.42 & 0.3615 & Not \\
& & & & & & & Significant \\
\hline
\end{tabular}

Note: $\mathrm{df}^{*}$ : Degree of freedom

\subsection{Removal of pollutants by POMES derived biochar}

The removal efficiencies of $\mathrm{COD}$, color and $\mathrm{NH}_{3}-\mathrm{N}$ in relation with pyrolysis temperature and holding time are as shown in Fig. 1 (a-c). The higher the temperature applied, the more complete is the carbonization process and therefore the surface area is increased as well as the development of pores within the biochar. When the temperature is high, the destruction of aliphatic alkyl as well as the ester groups takes place thus exposing the aromatic lignin core. This might be due to the escape of volatile substances inclusive of hemicellulose, cellulose and lignin from the biomass and forming channel structures during pyrolysis which in turn facilitate the increase of surface area and porous structure of biochar[7-8]. The pore-filling mechanism for organic pollutants is in relation to its adsorption capability which in turn is directly proportional to its microporous surface area. The greater the pore volumes and surface area promoted, the higher the adsorption for organic matters.

However, when the temperature is increased after the peak at $450^{\circ} \mathrm{C}$, the removal efficiency starts to drop. This is because the surface of the biochar has ruptured or sealed off due to the high temperature resulting in blockage of pores for adsorption [7]. Holding time does not play significant effect on the removal of organic pollutants but the removal efficiency is observed to decrease with increase of holding time. More time is allowed for the heat energy to break the surface bonds on the biochar thus reducing the functional groups available for interactions. However, noticing that the removal efficiency slightly increases when the holding time is approaching 180 minutes. At high temperatures, volatile organic matters will be removed from the biochar thus results in unblocking of the pores. Therefore, the slight increase in removal efficiency may be due to the fact that volatile matters are being removed from the pores when sufficient holding time is applied. Based on Fig. 1 (a-c), the constructed quadratic models readily fit with the experimental results.

The model fit summary of COD, color and $\mathrm{NH}_{3}-\mathrm{N}$ is to determine the degree of fitness of respective responses. The goodness of fit was proven by the determination of coefficient $R^{2}$ of $0.9585,0.9736$ and 0.8659 for the $\mathrm{COD}$, color and $\mathrm{NH}_{3}-\mathrm{N}$ respectively. A good fit model should have $\mathrm{R}^{2}>0.8$, thus this shows that the proposed models are fit [7]. $\mathrm{R}^{2}$ values closer to 1 will result in individual quadratic models to be statistically desirable, better fit and reasonable agreement to experimental data.The experimental conditions with the highest desirability were selected to be verified. 
a)

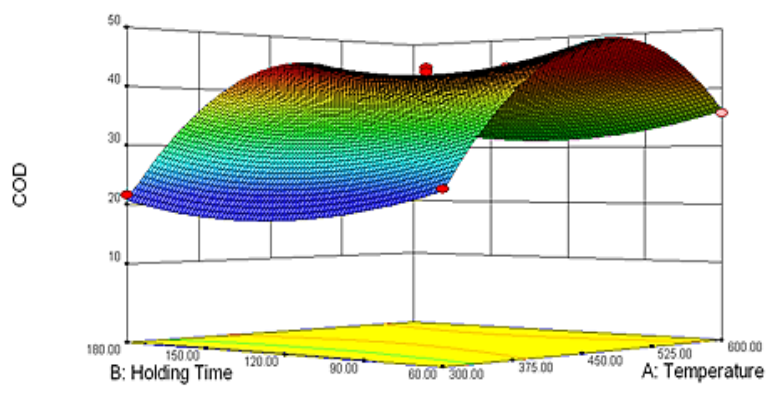

b)

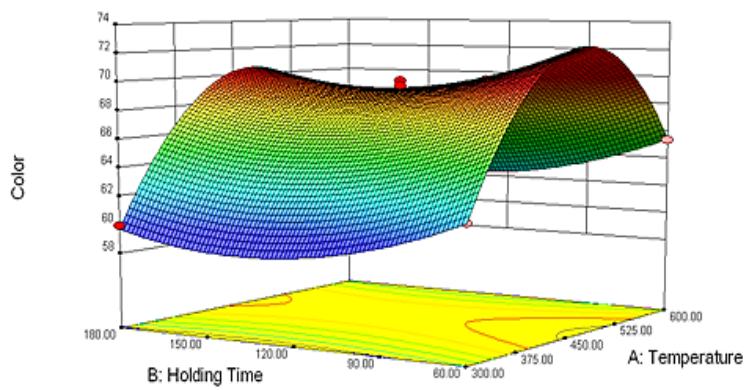

c)

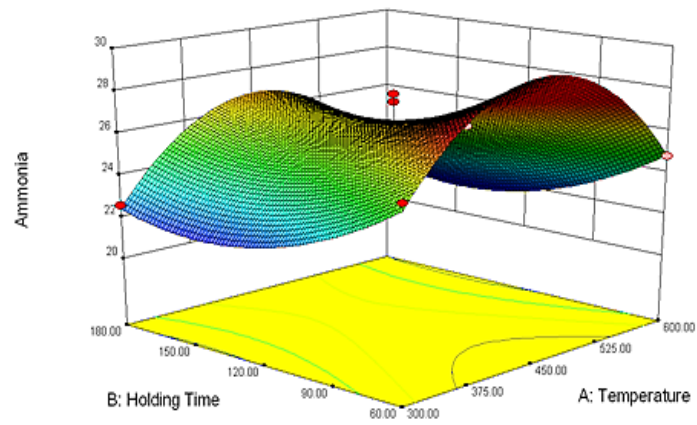

Fig.1.Three-dimensional response surface plot for removal efficiency of (a) COD, (b) color and (c) $\mathrm{NH}_{3}-\mathrm{N}$

\subsection{Process optimization}

Optimization was done simultaneously in this study by using Design-Expert ${ }^{\circledR}$ Software 10.0. One solution was chosen out of 28 solutions proposed by the software by taking into consideration of the solution desirability and also taking into account the removal efficiency as well. The closer the solution desirability to 1.0 indicates the closer the predicted responses to the target requirements. The independent variables proposed were taken into consideration as well to help minimize operational cost but at the same time with high removal efficiency of the leachate pollutants. The experiment was repeated by using the optimized values for the independent variables to check and compare between the actual 
and predicted removal efficiency. Based on Table 4, only a small percentage error was observed between the actual and predicted results under optimum conditions. The optimum operational conditions of POMES biochar for leachate treatment were found to be at $452^{\circ} \mathrm{C}$ of pyrolysis temperature and 66 minutes of holding time with pollutant removal percentages for COD, color and $\mathrm{NH}_{3}-\mathrm{N}$ of $44.26 \%, 70.20 \%$ and $30.56 \%$.

Table 4.Predicted and experimental result of POMES biochar at optimum conditions

\begin{tabular}{cccc}
\hline $\begin{array}{c}\text { Response } \\
\text { Parameter }\end{array}$ & $\begin{array}{c}\text { Actual Removal } \\
\text { Efficiency, \% }\end{array}$ & $\begin{array}{c}\text { Predicted Removal } \\
\text { Efficiency, \% }\end{array}$ & $\begin{array}{c}\text { Percentage } \\
\text { error, \% }\end{array}$ \\
\hline COD & 44.26 & 45.89 & 3.55 \\
Color & 70.20 & 71.93 & 2.41 \\
$\mathbf{N H}_{3}-\mathbf{N}$ & 30.56 & 29.22 & 4.38 \\
\hline
\end{tabular}

\section{Conclusions}

In this study, complicated landfill leachate from Sahom landfill was treated by biochar produced from POMES from Tian Siang Oil Mill Sdn. Bhd. with the removal percentage of $44.26 \%$ of $\mathrm{COD}, 70.20 \%$ of color and $30.56 \%$ of $\mathrm{NH}_{3}-\mathrm{N}$ under optimal conditions. The optimization process of biochar preparation was done by using RSM and the optimum conditions obtain were $452^{\circ} \mathrm{C}$ pyrolysis temperature and 66 minutes of holding time. It can be observed from the series of experiments done that the removal capability of biochar is greatly dependent on the method and parameters used to produce the biochar which directly and indirectly affects its porous structure. It can be concluded that the main factor affecting the adsorption efficiency of POMS biochar is the pyrolysis temperature as compared to holding time with only minor effects on its adsorption capability.

\section{References}

[1] S.N.S. Ismail andL.A. Manaf.The challenge of future landfill: A case study of Malaysia, J. Tox. Environ. Health Sci., 5(6), 86-96,(2013)

[2] K.Y. Foo., B. H.Hameed,An overview of landfill leachate treatment via activated carbon adsorption process, J. Hazard. Mater,171, 54-60, (2009)

[3] American Public Health Association (APHA), $A W W A \& W E F, 21^{\text {st }}$ Edition,(2005)

[4] D. Beneroso., J.M. Bermudez., A. Arenillas, J.A. Menendez ,Integrated microwave drying, pyrolysis and gasification for valorisation of organic wastes to syngas, Fuel, 132, 20-26, (2014)

[5] S. L. Low, Preparation, characterization and utilization of palm oil mill sludge biochar for copper removal. Undergraduate Thesis,Universiti Tunku Abdul Rahman, (2015)

[6] N. B. Azmi, M.J.K. Bashir., S. Sethupathi and C. A. Ng., Anaerobic stabilized landfill leachate treatment using chemically activated sugarcane bagasse activated carbon: kinetic and equilibrium study, Desalination and WaterTreatment,57, 3916-3927, (2016)

[7] A. Shehzad.,M.J.K. Bashir., S. Sethupathi and J.W. Lim,An insight into the remediation of highly contaminated landfill leachate using sea mango based activated bio-char: optimization, isothermal and kinetic studies. Desalination and Water Treatment, 57(47),22244-22257, (2016)

[8] M.B Ahmed Zhou, H.H. Ngo.and W. Guo, Insight into biochar properties and its cost analysis, Biomass and Bioenergy, 84,76-86, (2016). 